\title{
Protection of the Elderly from Abuse in Jordanian Law
}

\author{
Dr. Shatha Ahmad Al-Assaf, Assistant Professor in Constitutional Law, \\ Faculty of law, Isra University, Jordan. Email: shatha.alassaf@iu.edu.jo \\ The increase in the numbers of elderly globally and nationally has \\ led to more attention to the rights of this most vulnerable group and \\ the necessity to provide an effective legal protection against elder \\ abuse. The significance of this research lies in the fact that it is \\ necessary to protect elder people against abuse, as they are a \\ vulnerable and susceptible group. Hence, this research revolves \\ centrally around the extent to which the legal protection Jordanian \\ laws provide to elder persons against abuse compared to the \\ international standards. The research followed the analytical and \\ comparative method, by conducting a comprehensive review of the \\ Jordanian legal texts, analysing them and comparing them to the \\ international standard. This research concludes that the protection \\ provided by the Jordanian legislations and international \\ conventions against elder abuse is not sufficient. The research \\ provides several recommendations including criminalising all types \\ of elder abuse, imposing deterrent sanctions and explicit provision \\ for mandatory reporting of abuse cases.
}

Key words: Abuse; Elderly; Human Rights.

\section{Introduction}

Elder Abuse has become an issue of global concern due to the high life expectancy rate and increasing number of elderly people. The average life expectancy has reached seventy-eight (78) years in developed countries, while it reached sixty-eight (68) years in developing countries from 2010 to 2015 . This rate is expected to rise considerably by 2045 to 2050 to reach eighty-three (83) years in developed countries and seventy-four (74) years in developing countries (United Nations Population Fund (UNFPA) and HelpAge International, 2012).

In Jordan, there is a noticeable increase in the average life expectancy rate. In 1961, the average male and female life expectancy was fifty-four (54) years (Department of Statistics, 2012). However, in 2017, the average male and female life expectancy rose to 73.5 years. It is worth mentioning that the number of elderly people in Jordan is increasing rapidly 
according to the Jordanian Department of Statistics; the number of elderly people aged sixty (60) years and above is 547130 persons in 2017, accounting for $5.5 \%$ of the total population (Department of Statistics, 2017).

The increase in the life expectancy rate and the rapid increase in the numbers of elderly people, whether at the international or national level, resulted in shedding more light on the rights of elderly people and on how to legally protect such rights, the most important of which is their right for protection against abuse.

The significance of this research lies in the fact that it is necessary to protect elder people against abuse, as they are a vulnerable and susceptible group. Elder abuse results also in serious irreversible physical and psychological effects, especially given that it is difficult to detect Elder Abuse because they hesitate to report it to avoid retaliation, out of fear, shyness or inability to report it. There is no single specialised legal research about how to protect elder persons against abuse in the Jordanian Law.

Hence, this research revolves centrally around the extent to which the legal protection Jordanian laws provide to elder persons against abuse compared to the international standards. The research followed the analytical and comparative method, by conducting a comprehensive review of the Jordanian legal texts, analysing them and comparing them to the international standards in the provisions of international conventions ratified by the Hashemite Kingdom of Jordan; this was also done to see how compatible they are and if they meet their requirements, and also, by identifying the general comments issued by the international committees that clarify the obligations of the states' parties in the agreements and the standards listed in the non-binding international tools such as the United Nations Principles for Older Persons, Vienna International Plan of Action and Madrid International Plan of Action.

Therefore, the research will provide a definition of Elder Abuse, explain types of Elder Abuse and then identify the legal protection against Elder Abuse committed by their family members and legal protection against Elder Abuse at nursing homes.

\section{Elder Abuse: Definition and Types}

It is important to define Elder Abuse, list the different types of abuse which the elder persons could experience in general and determine the forms each type of abuse could take.

\subsection{Definition of Elder Abuse}

Several efforts were made to define Elder Abuse including, most prominently, the Hudson Taxonomy that defines Elder Abuse, given that this taxonomy considers it a term, which includes all types of mistreatment or abusive behaviour, directed against elder persons. 
Mistreatment could involve action or inaction, and could be one or more of the following: Physical, psychological or financial abuse or neglect which causes unnecessary suffering, compromises the quality of life, violates human rights, and causes injuries, pain or financial loss. A behaviour may be described as abusive, negligent or exploitative based on several criteria such as repetition, duration and cultural context, its impacts and severity (Hudson, 1991).

In an attempt to update the above-mentioned taxonomy, Anetzberger provided a definition, which relies on several levels. At the level of the Elder Abuse perpetrator, a perpetrator could be the elder person himself/herself, a trusted person, a stranger or an acquaintance, and abuse could be within a family or could be within an institutional framework. Abuse could also take the form of ill-treatment or neglect. At the level of the abuse motive, abuse could be intentional or unintentional. At the level of the harm caused to an elder person, a harm could be physical, psychological, social, financial or sexual (Anetzberger, 2012).

The World Health Organization (WHO) adopted a definition of Elder Abuse which was introduced by the International Network for the Prevention of Elder Abuse, i.e. "A single, or repeated act, or lack of appropriate action, occurring within any relationship where there is an expectation of trust which causes harm or distress to an older person" (World Health Organization (WHO), 2002).

Having analysed the previous definitions, the researcher adopts Anetzberger's definition since it encompasses all the sources of abuse, whether those committed by trusted persons or strangers, the different types of abuse, its motives and impacts. Anetzberger's definition was a real development of the Hudson Taxonomy because it has several clear levels. On the other hand, the WHO-approved definition is limited to the persons related to the elder person who are expected to be trusted persons. It does not encompass the abuse the elder person experiences on the part of strangers and does not refer to whether or not such related persons intentionally or unintentionally abuse elder persons.

\subsection{Types of Elder Abuse}

There are many types of Elder Abuse, and the elderly could be exposed to one of these types or a number of them; these types include the following:

1. Physical Abuse: Physical abuse means the intentional use of force, which results in injury, pain or impairment. This type includes a group of acts, which are committed against elderly such as beating, slapping or restraining. (Watson, 2013; Brandl et al., 2017).

2. Psychological Abuse: It is difficult to define and prove a psychological abuse (Payne, 2011); psychological abuse could be committed verbally; for example, threats or mockery or through actions such as imposing social isolation or neglect (Watson, 2013). 
3. Financial Abuse: Financial abuse involves several forms, which threaten the elders' properties or income whether through fraud, robbery and expropriation of lands or movable properties (Economic and Social Council, 2012; Fenge, and Lee, 2018).

4. Elder Neglect: Elder neglect refers to the situation in which the basic needs of the elderly exceed what is met for him/her. This type of abuse results from the inability of the elderly to obtain the requirements for life independently (Quinn and Tomita, 1997). Forms of neglect include delayed delivery of food to the elder person and delayed healthcare services. (Watson, 2013).

5. Sexual Abuse: Sexual abuse means causing an elderly to engage in a sexual activity through physical coercion, intimidation or emotional manipulation. An elderly is vulnerable to sexual abuse when he/she suffers from a physical or mental impairment and is unable to give an informed consent about sexual activity. (Teitelman, 2006).

\section{Elder Abandonment:}

According to the National Centre on Elder Abuse, elder abandonment is defined as "the desertion of an elderly person by an individual who has assumed responsibility for providing care for an elder, or by a person with physical custody of an elder." (National Center on Elder Abuse, 1998).

Since most elder abuses are committed against them by members of their families or at nursing homes, this issue will be investigated in the following sections.

\section{Domestic Abuse}

Domestic abuse involves types of coercive or controlling behaviour; the perpetrator uses social isolation, threat and stringent monitoring of the victim. This coercive behaviour constitutes harmful and dangerous impacts to the health and wellbeing of the elder person. The elder person could suffer from all types of abuse, including physical, psychological, sexual and financial abuse, and neglect (Wydall, Clarke, Williams and Zerk, 2018). Domestic abuse is committed by members of his/her family especially his/her adult sons or daughters or spouse. Women are more vulnerable to abuse than men (Croucher and Mackenzie, 2018).

Elder Abuse is often regarded as a hidden phenomenon. Hence, the lack of reliable statistics and information adds to the complexity of evaluating the scope of this problem (Economic and Social Council, 2012). Elder persons refrain from reporting domestic abuse for several reasons, the most prominent of which are: to maintain the privacy of family relationships; for fear of being embarrassed, insulted or disbelieved; being worried about the results of reporting abuse, such as the retaliation by the perpetrator against them and fearing the 
imprisonment of the perpetrator, and this could result in higher possibility of being placed in nursing homes (Quinn and Tomita, 1997).

At the level of legal protection of the elderly against abuse committed by their family members, the Jordanian Constitution of 1952, and its amendments, stressed the protection of the elderly, where it stipulated in Article (5/6) as follows:

"The law shall protect motherhood, childhood and the old-aged; and shall avail care for the youngsters and those with disabilities and protect them against abuse and exploitation".

The Jordanian Legislator paid much attention to providing protection against violence for all family members through the Law on Protection against Domestic Violence. The said Law defined Domestic Violence in Article (3) as the offenses against persons, which are committed by a family member against any other family member. A family member, pursuant to the provisions of this Law, means the spouse and relatives by blood up to the third degree, relatives by marriage up to the second degree, relatives by blood from the fourth degree and relatives by marriage from the third and fourth degrees, provided that the family member shall stay in the family house, and the child under the custody of a natural person or substitute family in accordance with the applicable legislations.

The Researcher argues that the Law on Protection against Domestic Violence did not define violence; rather, the Law limited violence to the crimes against persons. Therefore, this Law does not protect from the crimes against properties, which are committed by family members. Hence, it does not provide protection for an elder person against financial exploitation committed by his/her family members. If the Personal Status Law and Civil Code provide protection for the interdicted persons under a judicial ruling against foolishness or stupidity, such provisions do not protect elder persons, who are not interdicted, against financial abuse.

The Law of Protection against Domestic Violence, in Article 7/A/1, obligated the health, educational or social service provider in both public or private sector to report any incident of domestic violence committed against a legally incompetent person or a person with incomplete legal capacity upon being aware or informed of the same. Article 4/A/2 of the Law stipulated that the offended person shall agree to report violence if legally competent and if the act constitutes a felony or misdemeanor in accordance with the provisions of this Law. The Law imposed a punishment for violating these provisions, i.e. imprisonment for a period not exceeding one week and/or a fine not exceeding fifty Jordanian dinars or both penalties.

Informants are protected under the Law of Protection against Domestic Violence, in both Articles $4 / \mathrm{B}$ and $6 / \mathrm{B} / 5$, by stipulating that the identity of the informant shall not be disclosed unless otherwise is required by judicial proceedings. The Law obligated the Family 
Protection Department to take the necessary steps to protect informants in accordance with a regulation to be issued for this purpose; however, this regulation has not been issued so far.

The researcher believes that reporting on abuse cases should be encouraged through applying a more stringent punishment for not reporting, and that a regulation must be issued for protecting the informants of abuse cases.

Article 6 of the Law on Protection against Domestic Violence stipulated that the Family Protection Department must respond to every complaint, notice, request for protection or assistance in connection with domestic violence as quickly as possible. The Law also provides that other authorities shall, when receiving a complaint or notice about domestic violence, refer the same to the Family Protection Department. One of the procedures to be taken immediately by the Family Protection Department, when receiving any complaint, notice, or request for assistance or protection, is to record the complaint and prepare the necessary reports, then transport the aggrieved party to the nearest hospital, health centre or any other place as necessary. The Law, under Article (18), also stipulated that all the procedures and information must be strictly confidential in connection to the domestic violence lawsuits referred to any authority including courts of law.

The total number of physical and sexual abuses in 2018 against the elderly reached 58 cases as per the statistics of the Family Protection Department adjunct to the Public Security Directorate, of which 47 cases were of physical abuse and 11 cases of sexual abuse. It is worth mentioning that such statistics did not include psychological and economic violence, neglect and deprivation of rights. The NCHR also recommended that persons violating the rights of their parents, by abandonment and neglect must be criminalised under the Penal Code and that psychological violence must also be criminalised (National Center for Human Rights (NCHR), 2019).

Thus, it is important to highlight that these figures do not truly reflect all the incidents of violence and abuse committed against elder persons in the society; rather, these figures merely represent the cases referred to the Family Protection Department and only included the physical and sexual abuses in one year, i.e. 2018. The lack of standardised databases, classified according to age and cases of violence, makes it difficult to record all incidents of violence and will cause decision makers to be unable to have accurate information. In addition, there are no official data about reporting elder violence and abuse cases (AlNajdawi, 2017).

This is confirmed through the findings of a study in social work about abuse of the elderly who live with their families in Amman. The study was conducted on a sample consisting of 200 elder men and women where the questionnaires were distributed to them and an interview was made with eight of them. It was concluded that $56.5 \%$ of elder women get abused and the most repeated types of abuse elder persons experience include psychological 
abuse and social abuse including their family members being preoccupied away from them, and then health abuse. The source of abuse to elder persons was from their sons and daughters at $75 \%$ (Al-Sheikh, 2016).

By comparing the Jordanian law's protection of the elderly from violence with international standards, it is noted that attention was dedicated to the right of family protection and prevention of abuse and violence among its members in the international conventions and non-binding international tools. Countries shall, under Article 1/10 of the International Covenant on Economic, Social and Cultural Rights, make the necessary efforts to protect families and help them. Recommendation 29 of the Vienna International Plan of Action on Ageing urged governments and non-governmental organisations to establish social service departments to support families who keep elderly persons at home and to implement measures especially for the low-income families (Vienna International Plan of Action On Aging, 1983). In addition, such assistances must be provided to elder persons who live alone and to elder spouses who wish to stay at home (Committee on Economic, Social and Cultural Rights (CESCR), 1995).

General Recommendation No. 27, issued by the Committee on the Elimination of Discrimination against Women examined the reasons for physical as well as psychological, verbal and financial violence against elder women: the gender-based stereotypes, cultural, traditional and norm-based practices. As a result, elder women, especially those with a disability, experience harmful impacts in their family or other relationships. Several elder women suffer from neglect because of being regarded as a burden to their families since they are no longer productive or reproductive (Committee on the Elimination of Discrimination Against Women, 2010).

The Madrid International Plan of Action on Ageing (MIPAA) also encouraged to report against cases of ill-treatment especially by those persons who provide health and social services to combat abuse against elder persons (Madrid International Plan of Action on Ageing, 2002).

The Arab Charter on Human Rights (ACHR), in Article 2/33, stipulated that the State and society must ensure the protection of family, strengthening of family ties and protection of its members, prohibit different types of violence and ill-treatment among its members especially against a woman and child. ACHR also stipulated that the State and society must ensure the necessary protection and care for motherhood, childhood, old age and persons with special needs.

By comparing the protection provided by the Jordanian law against domestic violence, observations showed that despite the effective protection set forth in this Law including the mandatory reporting of violence, the issuing of protection order and the organising of settlements conducted in domestic violence cases, the Law has several loopholes. One of 
these loopholes is that the Law did not include provisions on the protection of elder persons against domestic violence and did not address the offense of the abandonment by the family of the elder person. In addition, the Law did not define domestic violence independently; rather, the Law limited domestic violence to the crimes against persons other than those against properties, opposite to the international standards which were reviewed and which dedicated attention to domestic violence against the elderly. The provisions in the Jordanian legislations, that health and social care providers must report violence, are in alignment with the provisions in the Madrid International Plan of Action on Ageing (MIPAA).

\section{Protection against Elder Abuse at Nursing Homes}

Elder persons could experience all forms of abuse in nursing homes. There are several sources of abuse in such nursing homes; abuse could be committed by the staff, other residents in the nursing home or visitors (Miller, 2017). Medication errors are most prominent form of abuse and neglect at nursing homes. These medication errors involve giving the wrong medication or dose, giving the medication at the wrong time, malnutrition, dehydration, and wheelchair injuries. Elder people experience sexual abuse from one of the staff working at the nursing homes, from another resident or visitor. Other new forms of abuse in such nursing homes include abuse through social media through posting the images of elder people in dehumanising conditions (Pitman and Metzger, 2018).

The gravity of abuse at nursing homes lies in the inability to identify the real dimensions for the spread of abuse in them. Abuse in nursing homes is rarely reported because elder persons fear from endangering their relationship with the staff working at the nursing homes. Reporting the abuse by the perpetrator, on the other hand, depends on his/her will to admit having committed abusive acts. In addition, because most acts of abuse are committed in the elder person's room without a single witness, this adds to the difficulty of recording such acts of abuse in the oversight reports (Blumenfeld Arens, Fierz, and Zún̆iga, 2017).

In 2017, the number of nursing homes in Jordan reached ten homes of which half of them belong to the voluntary sector and the other half to the private sector. Observations showed that there are no nursing homes affiliated to the governmental sector and that the Ministry of Social Development seeks to assist elder persons who need shelter through purchasing the services from the nursing homes totalling two hundred and sixty (260) Jordanian dinars per elder person a month, under a memorandum of understanding between the Ministry and some nursing homes (National Center for Human Rights, 2017).

A study was conducted on nursing homes in Jordan on a sample consisting of 146 elder persons aged above 60 years, and the sample constituted $50 \%$ of the study population. The study showed that $60.9 \%$ experienced violence of different types: $47.9 \%$ experienced physical violence, $65.8 \%$ experienced psychological violence and $68.5 \%$ experienced 
neglect. No single complaint was submitted to the relevant competent authorities (AlNawafleh, 2012).

The National Centre for Human Rights examined the conditions of elder persons in shelter homes and found out that elder persons are still experiencing a poor psychological state due to the lack of visits or few visits by their sons/daughters or relatives and due to the poor intervention by the psychiatrist to help them, and that there are elder persons suffering from neglect and exploitation (National Center for Human Rights, 2019).

At the level of the Jordanian Law, Article 8 of the Law No. 81 of 2012 on Licensing Nursing Homes and their Clubs stipulated that the Ministry of Social Development shall be entrusted to supervise the nursing homes and their clubs, and take the necessary inspection and followup measures such as obligating the nursing home or club to take all the measures ensuring the safety of elder persons and notifying the relatives of elder persons if they experience any harm.

The Law on Licensing the Nursing Homes and their Clubs gave the Minister of Social Development the right, if the nursing home or club violates the provisions of the Law, to take any of the following actions against them: Written warning and suspension of work for a period not exceeding three (3) months and closure of the home under Article 9/A of the above-mentioned law.

The National Centre for Human Rights recommended adding a provision to this Law that a person who commits physical and psychological abuse and exploits elder persons shall be held accountable, and that such act shall be deemed a violation for which the nursing home requires closing by the Minister of Social Development (National Centre for Human Rights, 2017).

The regulations on Licensing Nursing Homes of 2013, in Article 2/21, stipulated that nursing homes must adopt all the procedures, which guarantee the safety of elder persons and ensure that no elder person will experience abuse or violence. Article 18 of the same regulations required that a safe place must be provided for keeping the funds of residents and receipts shall be kept in each elder person's file.

Regarding the international standards, Principle 13 of the United Nations Principles for Older Persons, stipulated that elder persons must have appropriate access levels to institutional care, which secures protection and rehabilitation in a secure human environment.

Recommendation No. 34 of The Vienna International Plan of Action on Ageing asserted that wherever institutional care is necessary or inevitable for elder persons, the utmost effort must be made to ensure a quality of the institutional life aligning with the normal conditions of elder persons in their communities, with full respect for their dignity and privacy; States 
should be encouraged to define minimum standards to ensure a higher quality of institutional care.

The Special Rapporteur on the Right to Health pointed out that the care provided at care institutions could have a negative impact on the independence and dignity of elder persons. It expressed concern about non-reported cases of violence at such institutions (Economic and Social Council, 2012). Therefore, adequate protection must be provided to the elderly at nursing homes.

It should be noted that Jordanian legislations are compatible with the international standards since the Jordanian legislations assert that an elder person must lead a safe life and be protected against violence. However, both of them lack a deterrent punishment against a person who commits abuse inside the nursing homes especially if the perpetrator is a staff member of the nursing home. In addition, both of them allow and facilitate the reporting of elder abuse by the victim elder person, impose a mandatory instruction for staff to report abuse under penalty of liability and impose deterrent punishments for refraining from reporting abuse.

\section{Conclusions}

The seriousness of Elder Abuse lies in the several types of abuse, including physical, psychological, sexual and financial, and neglect and abandonment of elder persons. In addition, Elder Abuse has different sources; it could be committed by a family member, a staff member at the nursing home, health or social service providers or strangers. Therefore, encountering Elder Abuse needs effective legal protection. The research concluded the following:

1. There are several legal loopholes in the Jordanian Law regarding the protection of elder persons against abuse. One of these loopholes is that the Jordanian Penal Code did not contain special provisions on Elder Abuse to provide adequate protection to them. There are separate provisions in the Jordanian legislations, which provide the same protection for elder persons as other individuals without regard to the fact that they are a susceptible and vulnerable group.

2. As for international conventions, the situation was not better because there is no international convention for the protection of elder persons' rights. The protection of elder persons against abuse is limited to scattered provisions in the international conventions on human rights, which are applied in the same way as applied to other individuals. In addition, General Comment No. 6, of the United Nations Committee on Economic, Social and Cultural Rights (CESCR), paid attention to elder persons. General Recommendation No. 27 of the Committee on the Elimination of Discrimination against Women also paid attention to the rights of elder women. This was also done by a number of international 
non-binding tools such as the United Nations Principles for Older Persons, the Vienna International Plan of Action on Ageing and the Madrid International Plan of Action on Ageing.

3. This research found out, through comparing the protection of the Jordanian Law to the international standards in protecting elder persons against domestic abuse, that the Jordanian Legislator paid attention to organising the protection against domestic violence but did not include any provisions for the protection of elder persons, thus deviating from the provisions in international standards.

4. Jordanian legislations are compatible with the international standards in that an elder person must be protected against violence and abuse. However, both of them lack a deterrent punishment against the abuse perpetrator inside the nursing homes especially if the perpetrator is a staff member of the nursing home. In addition, both of them did not impose mandatory rules on staff members of nursing homes to report abuse under penalty of legal accountability.

\section{Recommendations}

1. All forms of Elder Abuse must be criminalised and a deterrent as well as a more stringent punishment must be imposed and applied against the perpetrator of abuse if the perpetrator is a member of the elder person's family, a staff member of the nursing home, a health and social care provider, and if the abuse is repeated. A more stringent punishment must also be applied in case of the abandonment of the elder persons and legal accountability must be organised for financial abuse and financial fraud, to include the novel methods of abuse such as websites and social media.

2. Stringent punishments must be applied to the nursing homes, through imposing high financial penalties, exposing them to the revocation of license if the necessary measures are not taken for prevention of Elder Abuse.

3. Mandatory reporting of Elder Abuse must be imposed on all persons who get to know of any incident of Elder Abuse. Refraining from reporting Elder Abuse must be criminalised under a deterrent punishment. In addition, protection must be provided to the informants of Elder Abuse incidents.

4. A national database must be created specifically for Elder Abuse through the information collected by police officers, healthcare providers and care providers at nursing homes, because there is no accurate information about the extent of Elder Abuse. Special statistics must be provided on Elder Abuse to identify all the dimensions, extent, reasons and results of Elder Abuse, and to conduct regular surveys.

5. Governmental units must be established to provide protection services for elder persons if they experience abuse. In addition, emergency shelters must be provided, where the confidentiality of procedures must be observed, privacy of the elder persons must be protected, and rehabilitative services must be provided to them after experiencing abuse. 
International Journal of Innovation, Creativity and Change. www.ijicc.net

Volume 15, Issue 4, 2021

\section{REFERENCES}

Al-Najdawi, A. (2017). The Reality of the Elderly in Jordan - a comparative analytical study. Amman: National Council for Family Affairs (NCFA).

Al-Nawafleh Q. (2012). Types of Violence Directed to the Elderly inside Elderly Nursing Homes in Jordan. The Arab Journal of Security Studies and Training, 28(55), 49-83.

Al-Shaikh, M. (2016). Abuses Against the Elderly Who Are Living with Their Families in the City of Amman. MSc Thesis, Amman: University of Jordan.

Anetzberger, G. (2012). An Update on the Nature and Scope of Elder Abuse. GENERATIONS / Journal of the American Society on Aging, 36 (3), 12-20.

Blumenfeld Arens, O., Fierz, K. and Zúñiga F. (2017). Elder Abuse in Nursing Homes: Do Special Care Units Make a Difference? A Secondary Data Analysis of the Swiss Nursing Homes Human Resources Project. Gerontology, 63(2), 169-179. DOI: 10.1159/000450787.

Brandl, B., Dyer, C., Heisler, C., Otto, J., Stiegel, L., and Thomas R. (2007). Elder Abuse Detection and Intervention/ A Collaborative Approach. New York: Springer Publishing Company.

Committee on Economic, Social and Cultural Rights (CESCR) (1996). Report on the twelfth and thirteen sessions, 1-19 May 1995, 20 November-8 December 1995. New York and Geneva: United Nations, Economic and Social Council, Official Records, Supplement No.2, Document No. E/1996/22.

Committee on the Elimination of Discrimination Against Women (2010). General Recommendation No. (27) on Older Women and Protection of Their Human Rights, Document No. CEDAW/C/2010/47/GC.1. Retrieved from https://documents-ddsny.un.org/doc/UNDOC/GEN/G10/472/53/PDF/G1047253.pdf?OpenElement.

Croucher R. and Mackenzie J. (2018). Framing Law Reform to address Elder Abuse. Macquarie Law Journal, 18, 5-14.

Department of Statistics (2012). Jordan Statistical Yearbook. No. 63. Amman: Department of Statistics.

Department of Statistics (2017). Jordan Statistical Yearbook, No. 68. Amman: Department of Statistics.

Economic and Social Council (2012). Report of the United Nations High Commissioner for Human Rights, Substantive Session of 2012 Geneva, 23-27 July 2012, Document No. E/2012/51. Retrieved from https://undocs.org/E/2012/51.

Fenge, L.A and Lee S. (2018). Understanding the Risks of Financial Scams as Part of Elder Abuse Prevention. British Journal of Social Work, 48(4), 906-923. DOI: 10.1093/bjsw/bcy037.

Hudson, M. (1991). Elder Mistreatment: A Taxonomy with Definitions by Delphi. Journal of Elder Abuse and Neglect, 3(2), 1-20.

Miller, C. (2017). Elder Abuse and Nursing/What Nurses Need to Know and Can Do About it. New York: Springer Publishing Company. 
International Journal of Innovation, Creativity and Change. www.ijicc.net

Volume 15, Issue 4, 2021

National Center for Human Rights (NCHR) (2017). The Second Periodic Report on Elderly Rights Situation in Jordan for 2017. Amman: NCHR.

National Center for Human Rights (NCHR) (2019). The Fifteenth Annual Report on Human Rights Situation in Jordan for 2018. Amman: NCHR.

Payne, B. (2011). Crime and Elder Abusel An Integrated Perspective. $3^{\text {rd }}$ ed. Illinois: Charles C. Thomas.

Pitman, J. and Metzger, K. (2018). Nursing Home Abuse and Neglect and the Nursing Home Reform Act: An Overview. NAELA Journal, (14), 137-154.

Political Declaration and Madrid International Plan of Action on Ageing (2002). New York: United Nations. Retrieved from https://social.un.org/ageing-workinggroup/documents/mipaa-en.pdf.

Quinn, M. and Tomita, S. (1997). Elder Abuse and Neglect. $2^{\text {nd }}$ ed. New York: Springer Publishing Company.

Teitelman, J. (2006). Sexual Abuse of Older Adults: Older Adults: Appropriate Responses for Health and Human Services Providers. Journal of Health and Human Services Administration, 29(2), 209-227.

The National Center on Elder Abuse (NCEA) and Westat, Inc. (1998). The National Elder Abuse Incidence Study, Final Report. Retrieved from https://acl.gov/sites/default/files/programs/2016-09/ABuseReport_Full.pdf.

United Nations Fund for Population Activities (UNFPA) and HelpAge International (2012). Ageing in the Twenty-First Century: A celebration and A challenge. New York: UNFPA, London: HelpAge International.

Vienna International Plan of Action On Aging (1983), New York: United Nations.

Watson, E. (2013). Elder Abuse: Definition, Types and Statistics, and Elder Abuse Mistreatment and Neglect Laws. Journal of Legal Nurse Consulting, 24 (2), 40-42.

World Health Organization (WHO) (2002). World Report on Violence and Health, Geneva: WHO.

Wydall S., Clarke A., Williams J. and Zerk R. (2018). Domestic Abuse and Elder Abuse in Wales: A Tale of Two Initiatives. British Journal of Social Work, 48 (4), 962-981. DOI: $10.1093 /$ bjsw/bcy056. 